\title{
Lithostratigraphic Classification Method Combining Optimal Texture Window Size Selection and Test Sample Purification Using Landsat 8 OLI Data
}

https://doi.org/10.1515/geo-2018-0045

Received June 5, 2018; accepted September 27, 2018

Abstract: Gray Level Co-Occurrence Matrix (GLCM), as a measure of spatial features has been used as supplemental information to improve image classification accuracy for lithological recognition. Window size is an important parameter for texture extraction, which will affect the extracted texture results. Besides, the existence of mixed pixels in image usually causes errors in test samples, which significantly influences the credibility of accuracy assessment. Thus, this paper proposes a lithological classification method combined with optimal texture window size selection and test sample purification. Firstly, optimal window size pre-estimated based on semivariogram was used to calculated GLCM texture of image. Secondly, based on multidimensional textural and spectral features, a support vector machine (SVM) classifier was employed to classify the image. Thirdly, using the proposed sample purification method and textural features of image, sample purification rules were created based on attribute coherence to remove the test sample points that conflicted with the rules. Finally, the validity of the semivariogram-based texture extraction window selection was verified by classifications based on Angular Second Moment (ASM) of different window sizes combined with spectral features. Also, the accuracies between different combinations of classifications were assessed by test samples with and without sample purification. Experimental results show that the pre-estimated texture window size can guarantee a classification result with high classification accuracy for lithological classification. The results also demonstrated that the accuracy of lithological classification based on spectral features and ASM textural features was the highest. The overall lithological classification accuracy and kappa value, without sample purification selected by stratified sampling, were respectively $87.4 \%$ and 0.84 , however those with sample purification were respectively $88.01 \%$ and 0.85 . The results show that the proposed method is capable of yielding more reliable lithostratigraphic identification.

Keywords: lithostratigraphic classification; GLCM; accuracy assessment; sample purification; semivariogram

\section{Introduction}

Lithostratigraphic classification is one of the most common fields in geology for application of remote sensing. Many studies have demonstrated that exploiting the spectral characteristics of minerals and rocks can effectively accomplish lithostratigraphic identification and mineral detection. The lithological information extraction approaches, based on spectral features, mainly focus on the conversion and enhancement of spectral features. These approaches include principal component analysis (PCA), matched-filtering, spectral angle mapping (SAM), band gap ratio (BR), relative absorption band depth (RBD), false color composite (FCC), and combinations of these methods [1-10]. For example, based on visible light nearinfrared (VNIR) and short-wave infrared (SWIR) bands of ASTER data, using the matching-filter, can identify limestone and dolomite; whereas the quartz rock and carbonate rocks can easily be identified through using the thermal infrared band (TIR) [11].

Due to local changes in mineral composition, terrain, vegetation cover, weathering, and other factors, spectral features within the same lithology category may have significant differences, and different rock types may have similar spectral features. Therefore, using only spectral features from the image for lithostratigraphic classification may limit accuracy. Thus, numerous studies have tried to

Yufang Qiu: China University of Geosciences, Beijing beijing, China *Corresponding Author: Dongping Ming: China University of Geosciences, Beijing beijing, China, E-mail: mingdp@cugb.edu.cn 
add texture information for lithostratigraphic recognition to achieve higher accuracy. Texture feature is a visual feature that reflects the homogeneity of the image without depending on color or brightness, which are internal features of object surface [12]. Texture features contain important information about the organization of an object's surface structure and contacts of the object with its surrounding environment [13]. Existing studies have shown that image texture features incorporated into lithostratigraphic classification can effectively improve classification accuracy [14-19]. Very accurate results in lithostratigraphic classification achieved when spectral features and Gray Level Co-Occurrence Matrix (GLCM) textural features were used together as noted by Mather et al. [20]. Subsequent studies also demonstrated the usefulness of GLCM for lithostratigraphic classification.

Window size is an important parameter for texture extraction process, too large or too small size will not be ideal for texture extraction. Semivariogram is a function of the distance between samples and the semivariance of samples. This feature spatially represents a spatial autocorrelation, reflected the spatial relationship between pixels on the image. The semivariogram method has been widely used to scale selection of remote sensing image segmentation [21]. In this paper, the optimal texture window size is estimated using semivariance, and the effectiveness of the method is verified by taking classification based on ASM of different window sizes and spectral features as an example.

Selecting an appropriate classification algorithm is an important step in determining the overall classification success [22]. Support vector machine (SVM), a nonparametric classifier, is a good performance classifier with the ability to handle multiple effective image features even though the sample size is small [22]. The known effective SVM algorithm can be applied to highdimensional data to avoid dimension issues. Moreover, the categories of seven rocks are linearly unseparable in feature space, many lithostratigraphic classification studies have demonstrated that the SVM classifier has good lithostratigraphic identification and classification performance [23-31]. In this study, because we attempt to combine multiple spectral and textural features for lithostratigraphic classification, the SVM algorithm is an appropriate selection.

Remote sensing image classification accuracy assessment is an absolutely necessary link in remote sensing classification technology. Accuracy assessment can effectively evaluate the classifier, and can also provide the final evaluation of image classification results [32]. Accuracy assessment can also provide an evaluation of the quality of classification for users [33], and therefore has important significance for application in remote sensing classification. Numerous researchers have studied remote sensing image classification accuracy assessments. Currently, the factors that affect accuracy assessment include three aspects: sampling design, reference data, and evaluation parameters [34]. Among them, sampling design is the most critical aspect, which not only determines the cost of the accuracy assessment, but also constitutes the basis of the accuracy assessment [35-37]. The reference data, mainly confined to reality and cost, will affect the quality of the test samples. The widely-used evaluation parameters contain overall accuracy (OA), kappa coefficient, producer's accuracy (PA), and user's accuracy (UA). In addition, Pontius and Millones [38] have proposed two evaluation parameters, quantity disagreement and allocation disagreement, that can describe the information in a confusion matrix and express classification accuracy better. These evaluation parameters are outputs of the confusion matrix.

Sampling design has a significant influence on deriving the confusion matrix. The sampling design process needs to consider three parts: sampling unit, sample set size, and sampling method [36]. The sampling unit contains point and polygon units. The sample set size means the number of test samples will affect the accuracy assessment results [39-41]. The sampling method includes simple random, stratified, and systematic sampling [40, 42]. In the process of selecting test samples, the existence of mixed pixels in the image and artificial error may cause misclassified samples, so that test samples may have errors. In the process of accuracy assessment, however, the error in test samples is often neglected, and all the errors are associated to classification error, which makes the assessment results unreliable. Therefore, this paper suggests that before accuracy assessment, test samples should be purified to reduce this error, which will make assessment results more objective and unbiased.

This paper uses semivariogram to pre-estimate the optimal window size for texture extraction and notes a key problem in an accuracy assessment program, the quality of test samples, and subsequently proposes a method which depends on the feature information to purify test samples and reduce its error. The effectiveness of optimal texture window size selection method and test sample purification technique are verified by experiments. This study used the Landsat 8 operational land imager (OLI) data, which can recognize rocks well $[19,43-45]$ and can be obtained free from the United States Geological Survey (USGS) and Earth Resources Observation and Science (EROS) data [46]. 


\section{Methodology}

\subsection{Workflow of Lithostratigraphic Classification}

The workflow for this method comprises several stages shown in Figure 1. The main stages are: semivariogram based optimal texture window size selection, GLCM based textural features extraction, SVM based lithostratigraphic classification, test sample set size calculation and selection, sample purification rules creation based on textural information of training samples and purified test samples, accuracy assessment based on test samples with sample purification, and results analysis.

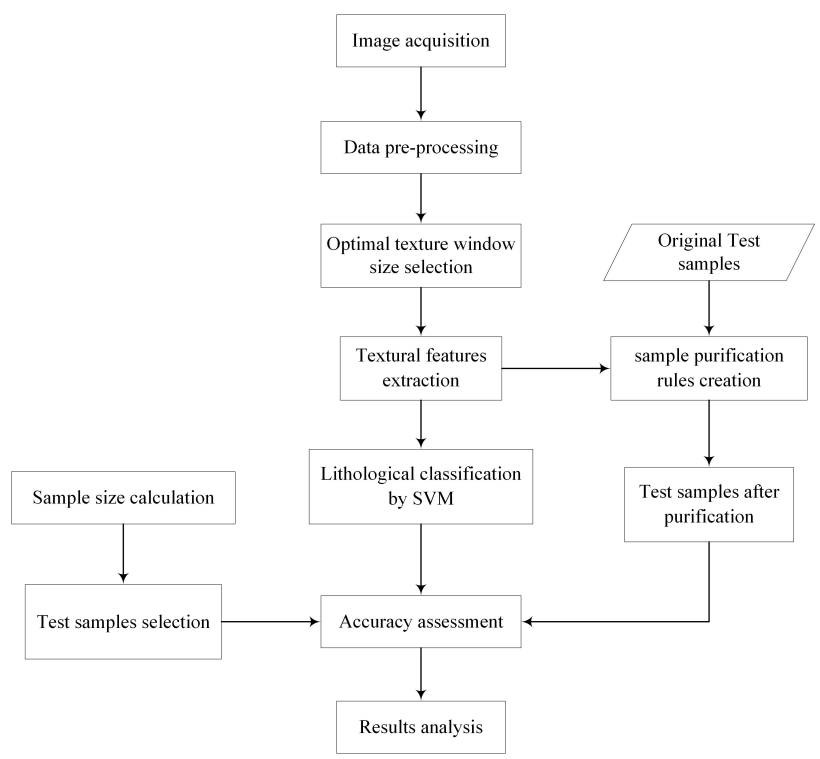

Figure 1: Flowchart of the lithostratigraphic classification method combining optimal texture window size selection and test sample purification technique

\subsection{Semivariogram-based Window Size Selection for Texture Extraction}

The semivariogram proposed by Matheron [47] is a spatial statistical method. The semivariogram can show how the variance of a variable varies with different sampling intervals on one image, which can represent the degree or scale of spatial variability. Semivariance $\gamma(\mathrm{h})$ is determined by Equation (1) [21].

$$
\gamma(h)=\frac{1}{2 N(h)} \sum_{i=1}^{N(h)}[X(i)-X(i+h)]^{2}
$$

where $h$ is the lag (or spatial sampling interval) and is a vector in both distance and direction because of the existence of anisotropy. $X(i)$ is a sample value at location $i$, and $X(i+h)$ is another sample value separated from $X(i)$ with the sample interval $h . N(h)$ is the total amount of pairs of $X(i)$ and $X(i+h)$.

The increasing and second derivative of semivariance are calculated from Equation (2) [21] and (3) [21] respectively.

$$
\begin{gathered}
\Delta \gamma(h)_{i}=\gamma(h)_{i}-\gamma(h)_{i-1} \\
\gamma^{\prime \prime}(h)_{i}=\left(\frac{\Delta \gamma(h)_{i}}{\gamma(h)_{i-1}}-\frac{\Delta \gamma(h)_{i-1}}{\gamma(h)_{i-2}}\right) \frac{\gamma(h)_{i-2}}{\Delta \gamma(h)_{i-1}}
\end{gathered}
$$

where $\left[\Delta \gamma(h)_{i}\right]$ is the increasing of semivariance and $\left[\gamma^{\prime \prime}(h)_{i}\right]$ is the second derivative of semivariance, $i$ represents the calculating times of the semivariogram with different sampling intervals.

The range of semivariogram (threshold of autocorrelation) associates the feature scale of the landscape. Within the range, the autocorrelation exists among variables, while beyond the range, autocorrelation may be untenable. So the range can be deemed as the measurement of similarity between variables, and it can indicate the size of a spatial object, a spatial phenomenon or a spatial pattern, as well as the size of texture primitive. So the range of semivariogram can be used to estimate the optimal texture window size. More specifically, the range is set as the sampling interval $h_{i}$ corresponding to $\left[\Delta \gamma(h)_{i}\right]$ whose value is first less than or equal to zero with the increasing of $h$ and $\left[\gamma^{\prime \prime}(h)_{i}\right]$ whose value is first greater than or equal to zero with the increasing of $h$. More details, please refer to Section 4.1.

\subsection{Principles of Textural Feature Expression Based on GLCM}

GLCM is a common method for describing texture by studying the spatial correlation of pixel gray. As a statistical method, it has been widely used to extract the features of texture statistics from images. Based on GLCM, Haralick [13] proposes 14 textural features to extract from the texture statistics of images. Commonly used features for lithostratigraphic classification include Angular Second Moment (ASM), Homogeneity (Homo), Entropy (Ent), Correlation (Cor), and Contrast (Con) [48,49]. In this study, taking into account the time consumption, four important features, ASM, Ent, Cor, and Con, are selected for extracting textural features of the study area.

ASM, known as Uniformity or Energy, is the sum of squares of the elements value in the GLCM [48]. It reflects 
gray scale distribution uniformity and texture roughness of the image [50]. ASM is high when the image is a uniform and regularly changing texture pattern. ASM is extracted by Equation (4) [51].

$$
A S M=\sum_{i} \sum_{j}\{P(i, j \mid d, \theta)\}^{2}
$$

Ent, determined by Equation (5) [48], shows the complexity of the image [50]. The higher the Ent, the more complex image [48].

$$
E n t=-\sum_{i} \sum_{j} P(i, j) \log P(i, j \mid d, \theta)
$$

Cor, calculated by Equation (6) [48], measures the dependency of grey levels in the row or column direction [15]. Therefore, it reflects the correlation between local grey levels [52]. Cor is high when grey levels of an image are even [50].

$$
\operatorname{Cor}=\frac{\sum_{i} \sum_{j}(i j) P(i, j \mid d, \theta)-\mu_{x} \mu_{y}}{\sigma_{x} \sigma_{y}}
$$

Con, extracted by Equation (7) [51], measures the distribution of values in the GLCM and local changes in the image [15]. It reflects the clarity of the image and the depth of the textural grooves [53]. Con is high when the textural groove is deep, and the image is clear; the Con is low when the textural groove is shallow, and the image is fuzzy [50].

$$
\text { Con }=\sum_{i} \sum_{j}(i-j)^{2} P(i, j \mid d, \theta)
$$

Where $P(i, j \mid d, \theta)$ is a GLCM with step size $d$ and angle $\theta$, (i, $j$ ) means position. $\mu_{x}, \mu_{y}, \sigma_{x}$, and $\sigma_{y}$ are the means and standard deviations of rows and columns.

For this paper, the step sizes of one and direction of $45^{\circ}$ were set for computing the $P(i, j \mid d, \theta)$. The window size is selected by semivarogram. Then, according to Equations (4)-(7), ASM, Ent, Cor, and Con can be extracted.

\subsection{Support Vector Machine Classifier}

The SVM studied by Vapnik et al. [54-57] is a supervised machine learning algorithm which is based on statistical learning theory. The SVM seeks a hyperplane that satisfies the classification requirements, and ensures the distance between the training data and hyperplane is as far as possible. The learning strategy of SVM is through interval maximization, which is applied to convex quadratic programming problem solving.

The rationale of SVM can be summarized as follows [58]:
1. Map the points in low-dimensional space into highdimensional space based on the kernel function, so that they become linearly separable.

2. Use the principle of linear division to determine the optimal hyperplane which can separate the two classes correctly, and the classification margin is at the maximum. The classification margin is the gap between the hyperplane and the closest training samples. The closest training samples are support vectors.

The optimal classification function is [58]:

$$
f(x)=\operatorname{sign}\left(\sum_{i=1}^{n} a_{i} y_{i} K\left(X, X_{i}\right)+b\right)
$$

where $\left\{\left(X_{1}, y_{1}\right),\left(X_{2}, y_{2}\right), \ldots,\left(X_{n}, y_{n}\right)\right\}$ are training samples, $X_{i} \in \mathrm{R}^{n}, y_{i} \in(-1,1) . X=\left(X_{1}, X_{2}, \ldots, X_{n}\right)$ means the input vectors, $X_{i}(i=1,2, \ldots, N)$ are support vectors. $a_{i}$ and $b$ are undetermined coefficients of the hyperplane. $K\left(X, X_{i}\right)$ is the kernel function including Linear, Polynomial, Radial Basis Function (RBF), and Sigmoid Kernel. The Radial Basis Function is chosen for this study.

\subsection{Accuracy Assessment Combining Test Sample Purification}

\subsubsection{Sample Set Size}

For simple random sampling, an appropriate test sample size could be estimated by Equation (9) [59].

$$
n=\frac{z^{2} O(1-O)}{d^{2}}
$$

where $O$ is the estimated overall accuracy that we expect to achieve, $z$ is the value from the standard normal distribution corresponding to the confidence level ( $z=1.96$ corresponding to a $95 \%$ confidence level, $z=1.645$ corresponding to a $90 \%$ confidence level) and $d$ is the allowable range of error for the confidence interval of $O$.

For stratified sampling, we assumed the sampling cost of every class is the same, and an appropriate test sample size could be calculated from Equation (10) [59] and (11) [59].

$$
n=\frac{\left(\sum W_{i} S_{i}\right)^{2}}{[S(\hat{O})]+(1 / N) \sum W_{i} S_{i}{ }^{2}} \approx\left(\frac{\sum W_{i} S_{i}}{S(\hat{O})}\right)^{2}
$$

where

$$
S_{i}=\sqrt{U_{i}\left(1-U_{i}\right)}
$$


where $N$ is the number of pixels in the study area, $S(\hat{O})$ is the standard error of the targeting overall accuracy, $W_{i}$ is the occupied ratio of area by class $i, S_{i}$ is the standard deviation of class $i$, calculated from Equation (11), and $U_{i}$ is the user's accuracy of class $i$.

\subsubsection{Sample Purification}

A confusion matrix based on good test samples could more objectively depict classification accuracy. Therefore, before using test samples to assess accuracy, sample purification of test samples is necessary to ensure the credibility of the lithostratigraphic classification accuracy. The method of sample purification is based on attribute coherence, which means for the same class the test samples would have similar properties as the training data. The attribute contains both spectral and textural features. Therefore, it is necessary to select appropriate attributes to identify different classes.

The method used to establish sample purification rules are:

$$
\begin{aligned}
& P_{i j}=\left\{(i j) \mid \text { Test_ } F_{i j}>\min \left(\text { Training_ } F_{i j}\right)\right\} \\
& P_{i j}=\left\{(i j) \mid \text { Test_ } F_{i j}<\max \left(\text { Training_ } F_{i j}\right)\right\}
\end{aligned}
$$

where $P_{i j}$ is the sample purification rule of class $i$ based on feature $j, i$ and $j$ represent different classes and different features, Test_ $F_{i j}$ and Training_F $F_{i j}$ mean the value of feature $j$ for test sample and training sample of class $i$. The $\min \left(\right.$ Training_ $F_{i j}$ ) and $\max \left(\right.$ Training_ $\left.F_{i j}\right)$ represent minimum and maximum values of feature $j$ for the training sample of class $i$. Features contain spectral and textural features in this method.

For training samples of class $i$, if its median value of feature $j$ is the largest and the gap between the other categories is also the largest, we will use Equation (12) to obtain $P_{i j}$; conversely, if the median value of feature $j$ is the smallest and the gap between the other categories is also the largest, Equation (13) will be applied to derive $P_{i j}$. In addition, the rest of the classes correspond to Equations

(12) and (13).

The process of sample purification is as follows:

1. Compute the features information for training samples of each class, and draw a chart based on the median values of the features;

2. According to the chart, determine to use either Equation (12) or Equation (13) to create and establish sample purification rules;
3. Purify the test samples, according to the rules derived from step two to exclude the sample points that conflict with the rules.

\section{Study Area and Data}

\subsection{Study Area}

The study area (Figure 2) is located in the northwest margin of the Tarim Basin, which lies in the Xinjiang province of Western China, with an eastern longitude range from $77^{\circ} 35^{\prime}$ to $78^{\circ} 10^{\prime}$ and a northern latitude range from $40^{\circ} 0^{\prime}$ to $40^{\circ} 25^{\prime}$. The average elevation of the study area is approximately $1885 \mathrm{~m}$. The region has a temperate-continental climate, resulting in low precipitation, poor vegetation development, and good rock outcrops, which is the ideal area for using satellite remote sensing technology for geological research. The main stratigraphic units in this area include $\epsilon-O, S, D, C-P, N_{2}, Q_{1}, Q_{3-4}[60]$. The 1:200,000 geological map (Xinjiang Geological Survey, 1965a, b) of the area was used as the reference map [60], shown in Figure 3. Main rock units in the study area and their lithostratigraphic description are shown in Table 1.

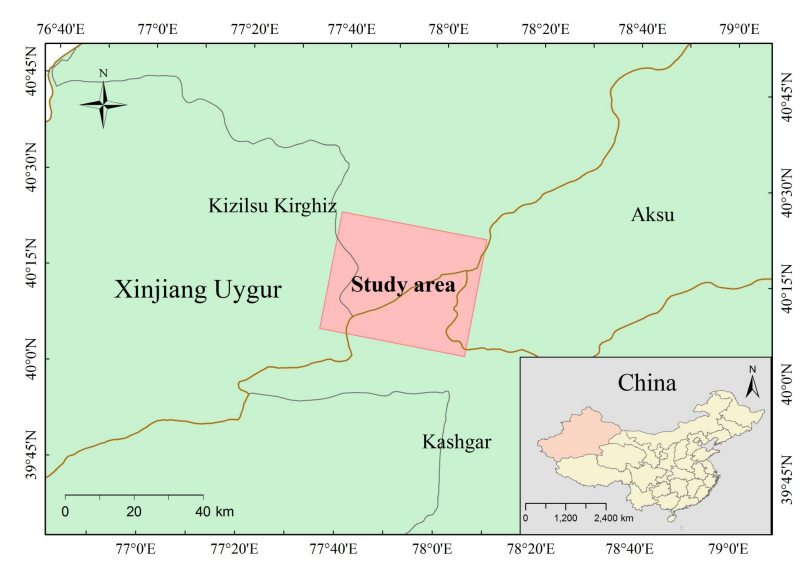

Figure 2: Location of study area.

\subsection{Data and Data Pre-processing}

The image used in the present study was acquired by Landsat 8 OLI on July 30, 2013. The data (LC81480322013211LGN00), was provided by USGS EROS data center [46]. The image has $0.75 \%$ of cloud cover, which mainly concentrated in the upper corner. There- 
Table 1: Description of lithostratigraphic units in the study area.

\begin{tabular}{|c|c|c|c|}
\hline Rock Units & Local Name of Rock Units & Geological Time & Lithological Description \\
\hline$\epsilon-0$ & Qiulitage Group & Cambrian & Dolomite and gray stratified limestone \\
\hline$S$ & Kepingtage Group & Ordovician & $\begin{array}{l}\text { Gray-green mudstone; quartz siltstone; } \\
\text { muddy siltstone; gray-green sandstone; } \\
\text { yellow-gray bottom sandstone }\end{array}$ \\
\hline D & Shalayimu Group & Silurian & $\begin{array}{l}\text { Light green, red, purple-brown sandstone; } \\
\text { flood layer }\end{array}$ \\
\hline C-P & $\begin{array}{l}\text { Kangkelin and Bieliangjin } \\
\text { Groups }\end{array}$ & Devonian & $\begin{array}{l}\text { Light gray, gray-red, gray limestone; } \\
\text { gray-black sandstone }\end{array}$ \\
\hline $\mathrm{N}_{2}$ & Cangzongse Formation & Carboniferous & $\begin{array}{l}\text { Flood layer; pale-brown sandstone; } \\
\text { pale-brown mudstone; pale-brown siltstone }\end{array}$ \\
\hline $\mathrm{Q}_{1}$ & - & Tertiary & Flood layer \\
\hline $\mathrm{Q}_{3-4}$ & - & Quaternary & Sandy soil; sandy clay \\
\hline
\end{tabular}

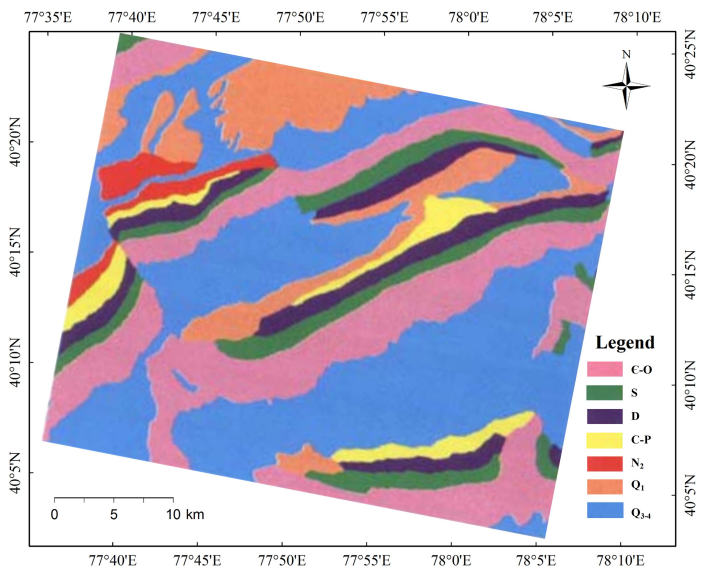

Figure 3: The lithostratigraphic map of the study area.

fore, no cloud was presented in the image of study area, as shown in Figure 4. Figure 4 shows the false color composition of the study area. The study uses the multispectral and panchromatic data of the image, which are detailed in Table 2. The images we obtained are Level-1 digital number data products that have been radiometrically and geometrically corrected by USGS. The images were processed as follows:

1. Radiometric calibration was conducted for VNIRSWIR images to acquire the top of atmosphere reflectance data.

2. FLAASH atmospheric correction with the MidLatitude Summer atmospheric model and the rural aerosol model were conducted for the top of at- mosphere reflectance data to acquire the surface reflectance data.

3. For ease of visually interpretation and enhancing the separability between different category, the surface reflectance data were fused with the panchromatic band by Gram-Schmidt Pan Sharpening.

4. C-correction, a topographic correction method based on the linear relationship between the image pixels and the cosine of the solar relative incidence angle [61], was conducted for the images to remove the shadows effect. ASTGTM DEM (Figure 5) with $30 \mathrm{~m}$ spatial resolution was used in Topographic Correction process.

After data pre-processing, the fused VNIR-SWIR bands were used to extract texture features. All the procedures of data processing in this section were conducted in ENVI 5.1.

\subsection{Vegetation Elimination in Remote Sensing Images}

A small amount of vegetation was present in the used image, which needs to be considered, as shown in Figure 4. In this figure, the vegetation is shown in magenta. The texture features are described based on the spatial variability associated with the digital number (DN) of the local pixels. Therefore, the vegetation in the image will hide or dam- 
Table 2: Landsat 8 Operational Land Imager (OLI) band information.

\begin{tabular}{lll}
\hline Band Name & Wavelength $(\mu \mathrm{m})$ & Spatial Resolution $(\mathrm{m})$ \\
\hline Band 1 Coastal & $0.433-0.453$ & \\
Band 2 Blue & $0.450-0.515$ & \\
Band 3 Green & $0.525-0.600$ & 30 \\
Band 4 Red & $0.630-0.680$ & \\
Band 5 NIR & $0.845-0.885$ & \\
Band 6 SWIR 1 & $1.560-1.660$ & \\
Band 7 SWIR 2 & $2.100-2.300$ & 15 \\
\hline Band 8 Pan & $0.500-0.680$ & \\
\hline
\end{tabular}

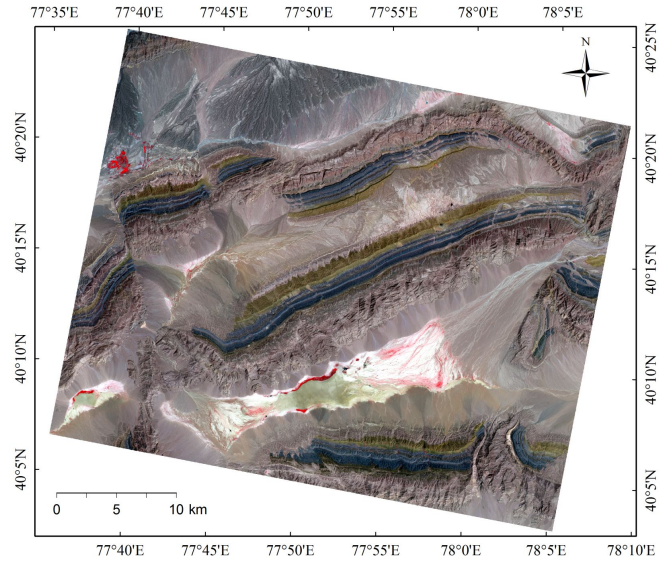

Figure 4: Landsat 8 false color composite image of the study area $(R$ $=$ band 5 (NIR, 0.845-0.885), G = band 4 (Red, 0.630-0.680), and $\mathrm{B}$ $=$ band $3($ Green, $0.525-0.600)$ ).

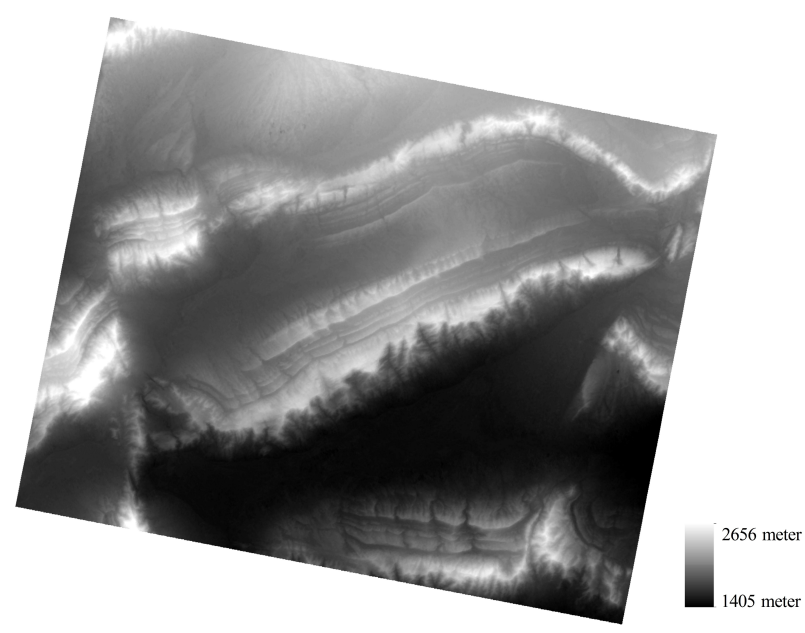

Figure 5: ASTGTM DEM of the study area.

age the texture information. In order to remove vegetation, Equation (14) [62, 63] was used to calculate the normalized difference vegetation index (NDVI). In this paper, the NDVI threshold is set to 0.3 , marking off the vegetation pixels, which in Figure 6 is green.

$$
N D V I=\frac{N I R-R}{N I P+R}=\frac{\text { band } 5-\text { band } 4}{\text { band } 5+\text { band } 4}
$$

Figure 6: Vegetation pixels in green with $0.3<$ normalized difference vegetation index $(\mathrm{NDVI})<1.0$

\section{Experiments}

\subsection{Window Size Selection for Texture Extraction}

As shown in Figure 7(a), the representative sampling area with a size of $600 \times 600$ pixels is used for calculating semivariance in this experiment. In order to accurately reflect the variation of semivariance along the spatial sampling distance, the lags are set from 3 to 45 , and the step of the lag is set as 2 . Band 6 with the largest standard deviation, contains the maximum amount of information. To reduce the amount of computation, the semivariograms in the horizontal and vertical directions are calculated by band 6 of 


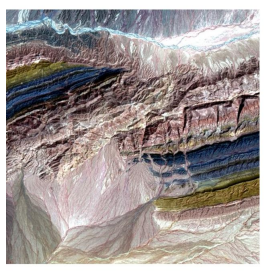

(a)

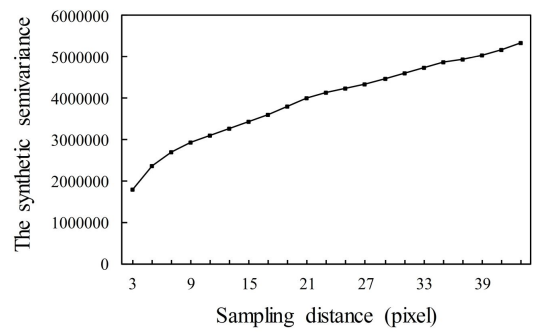

(b)
Figure 7: (a) the sampling area with a size of $600 \times 600$ pixels; and (b) synthetic semivariograms.

the sampling area images. The synthetic semivariances are the average of the horizontal and vertical semivariograms, displayed in Figure 7(b).

From Figure 7(b), it can be seen that the range of the synthetic semivariogram is not obvious. To achieve pre-estimation of the reasonable window size for texture extraction, the increasing of the synthetic semivariance $\left[\Delta \gamma(h)_{i}\right]$ and second derivative of the synthetic semivariance $\left[\gamma^{\prime \prime}(h)_{i}\right]$ are displayed in Figure $8(\mathrm{a})$ and (b). According to Figure 8, the sampling distance for the image shown in Figure $8(a)$ is 11 , corresponding to a $23 \times 23$ spatial window, and the sampling distance for image shown in Figure 8 (b) is 15 , corresponding to a $31 \times 31$ spatial window. By employing the texture window size pre-estimation method proposed in Section 2.2, the theoretical optimal texture window size is determined as $31 \times 31$.

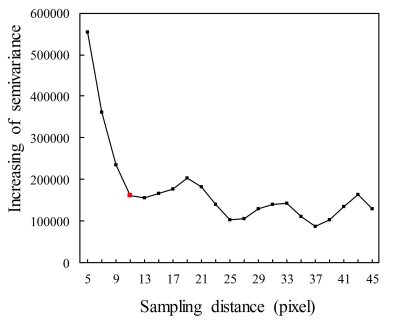

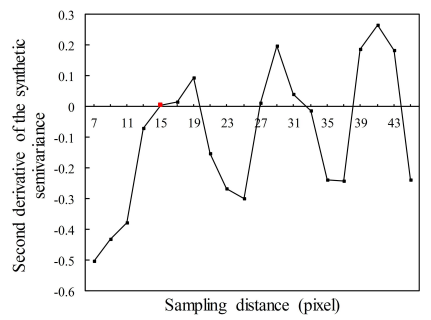

(b)
Figure 8: Computed results of: (a) the increase of the synthetic semivariance; (b) the second derivative of the synthetic semivariance. of GLCM, ASM, Ent, Cor, and Con, were calculated to obtain 28 texture images. In order to study the effectiveness of the different texture images for lithostratigraphic identification and create sample purification rules, the texture values of the training samples were extracted from the texture images. The median texture value of each category is shown in Figure 9.

Figure 9 provides the following information:

1. The ASM feature distinguishes $Q_{3-4}$ from other rock types well, and the value calculated from band 5 is largest. $Q_{3-4}$ is generally larger on ASM values, which may be because its texture is more uniform and regular-changing than other rock types.

2. $\mathrm{N}_{2}$ has the highest Ent value, which indicates its surface is most complex. $\mathrm{Q}_{3-4}$ has the lowest Ent, TF5, and TF6 values, which means it is simpler than other rocks.

3. The Cor feature can separate $Q_{1}$ from other rocks. The Cor values of $Q_{1}$ are relatively small, which means $Q_{1}$ has a small local correlation on the image. Cor values curves of $S$ and $Q_{3-4}$ fluctuate greatly, which may due to the fact that texture images derived from different bands have a variable effect on rock identification [19].

4. $\mathrm{N}_{2}$ shows a significant difference in the Con feature compared to other rock types, which may result from its deep textural trench. From TF1 to TF7, between the Con values, there is an obvious difference between $\epsilon-O$ and $C-P$, and the between $S, D$, and $Q_{1}$.

In short, the application of GLCM textural features to the classification process can help improve the separation of different rock types. For the same texture, the texture images obtained from different bands have different sensitivities for rock identification. The different textures calculated in the same band have different sensitivities for lithostratigraphic identification as well. For example, an ASM image derived from band 5 distinguishes $Q_{3-4}$ from other rock types, however, Ent and Con images calculated from band 5 separate $\mathrm{N}_{2}$ well. Overall, different texture images have abilities to identify different rocks.

\subsubsection{Feature Selection}

In this paper, we treat seven spectral bands as a whole, for ASM, Ent, Cor, and Con also. Then, the spectral and texture are combined in the SVM classifier for lithostratigraphic classification. As shown in Table 3, a total of 15 combinations of spectral and texture features are possible. Optimum Index Factor (OIF) [64] is calculated for combinations in Series 2 and Series 3 to select the optimal comof $31 \times 31$ is used for extracting Ent, Cor, and Con. According to seven bands of Landsat 8 data, four textural features 

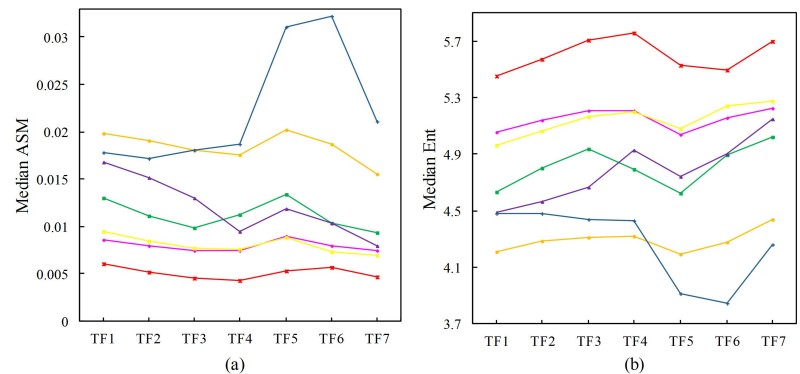

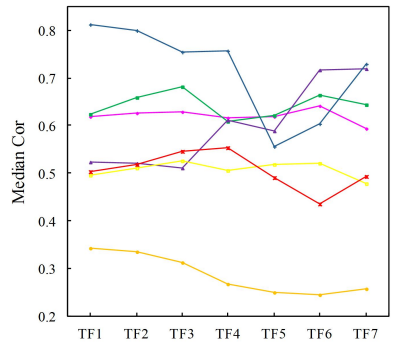

(c)

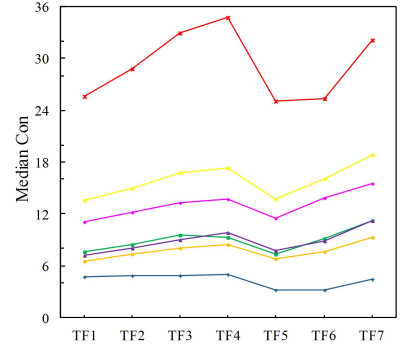

(d)

C-P $\quad *-\mathrm{N}_{2} \quad \rightarrow \mathrm{Q}_{1} \quad-\mathrm{Q}_{3-1}$
Figure 9: Median texture value for the seven rock types: (a) median ASM value; (b) median Ent value; (c) median Cor value; and (d) median Con value. TFi means the texture images were derived from spectral band $i$.

binations. The correlation between band 1 and the texture features, with the standard deviation of them, is used to calculate the index. The correlation matrix between band 1 and the texture features calculated from band 1 is presented in Table 4.

In Series 2, SF+ Ent+ Con has the largest OIF value, and the second largest is SF+ Cor+ Con. For Series 3, the optimal combination is selected by calculating the OIF index of texture feature combinations. For example, for SF+ $\mathrm{ASM}+\mathrm{Ent}+\mathrm{Cor}$, we calculate the OIF index of ASM+ Ent+ Cor. And Ent+ Cor+ Con has the largest OIF value. Therefore, based on band 1, optimal selection of Series 2 and Series 3 are respectively SF+ Ent+ Con and SF+ Ent+ Cor+ Con. Wei et al. [19] demonstrated that using textural features extracted from multiple spectral bands has a better performance than that from a single spectral band to aid spectral information for lithostratigraphic classification. Hence, combinations of spectral and texture features for lithostratigraphic classification is shown in Table 5.

\subsection{Lithostratigraphic Classification}

There are seven rock types in the study area including $\epsilon-\mathrm{O}, \mathrm{S}, \mathrm{D}, \mathrm{C}-\mathrm{P}, \mathrm{N}_{2}, \mathrm{Q}_{1}$, and $\mathrm{Q}_{3-4}$, detailed in Table 1. The training sample amounts of each rock type are displayed in Table 6.
The training samples of these rocks were selected based mainly on the reference map. Based on GLCM, four features, including ASM, Ent, Cor, and Con, were extracted. In this paper, a SVM classifier was used to classify the combinations of texture and spectral images. The combinations of texture and spectral images classified by SVM are: spectral features (SF), SF+ASM, SF+Ent, $\mathrm{SF}+\mathrm{Cor}, \mathrm{SF}+\mathrm{Con}, \mathrm{SF}+$ $\mathrm{Ent}+\mathrm{Con}, \mathrm{SF}+\mathrm{Ent}+\mathrm{Cor}+\mathrm{Con}$ and $\mathrm{SF}+\mathrm{ASM}+\mathrm{Ent}+\mathrm{Cor}+\mathrm{Con}$, as shown in Table 5.

\subsection{Accuracy Assessment Combining Sample Purification}

\subsubsection{Calculation of Sample Set Size}

Before application, classification maps constructed from images should be assessed for accuracy [34]. An accuracy assessment process begins with sampling design. The first step in sample design is to calculate sample set size for the test samples. With $z=1.96, O=0.74$, and $d= \pm 5 \%$, the resulting sample set size from Equation (9) is $n=295$, marked as sample A1. Dependent on sample A1, the first accuracy assessment is carried out, and the mean user's accuracies $\left(U_{i}\right)$ are shown in Table 7.

Because $N$ is adequately large (exceeding six million pixels in this study), for Equation (10), the second item in the denominator can be neglected. Once $n$ is defined, proportional allocation [65] can be used to determine the sample size per strata in this paper. In addition, the stratified sampling [42, 66-68] strategy is employed and systematic sampling $[36,59]$ is then applied for every class. In this research, test samples select from the entire original image with step sizes of 80 pixels row by row and column by column. Table 7 provides information that is needed to calculate sample set size from Equation (10). Among them, the mapped area proportions $\left(W_{i}\right)$ is the mean of all classification results. Based on Table 7, specified $S(\hat{O})$ for 0.01 , the sample set size calculated from Equation (10) is $n=1246$, marked as sample B1. $n$ is the overall sample set size. The allocation of the number of samples per class was determined by proportion, detailed in Table 8 . When we applied sample purification rules (Table 9) to samples A1 and B1, we derived sample A2 and B2, detailed in Table 8.

\subsubsection{Creation of Sample Purification Rules}

According to problems that were mentioned in Section 1 , test sample purification was implemented to improve the reliability of classification accuracy. Based on Section 
Table 3: Different combinations of spectral and textural features

\begin{tabular}{|c|c|c|c|}
\hline Series 1 & Series 2 & Series 3 & Series 4 \\
\hline$S F+A S M$ & $\mathrm{SF}+\mathrm{ASM}+\mathrm{Ent}$ & SF+ ASM+Ent+ Cor & $\mathrm{SF}+\mathrm{ASM}+\mathrm{Ent}+\mathrm{Cor}+\mathrm{Con}$ \\
\hline SF+ Ent & $\mathrm{SF}+\mathrm{ASM}+\mathrm{Cor}$ & SF+ ASM+Ent+ Con & - \\
\hline $\mathrm{SF}+\mathrm{Cor}$ & $\mathrm{SF}+\mathrm{ASM}+\mathrm{Con}$ & $\mathrm{SF}+\mathrm{ASM}+\mathrm{Cor}+\mathrm{Con}$ & - \\
\hline $\mathrm{SF}+\mathrm{Con}$ & $\mathrm{SF}+\mathrm{Ent}+\mathrm{Cor}$ & SF+ Ent+ Cor+ Con & - \\
\hline- & $\mathrm{SF}+\mathrm{Ent}+\mathrm{Con}$ & - & - \\
\hline- & $\mathrm{SF}+\mathrm{Cor}+\mathrm{Con}$ & - & - \\
\hline
\end{tabular}

Table 4: Correlation matrix between band 1 and the texture features calculated from band 1. TF1 means the texture features were derived from spectral band 1; Stdev is the abbreviation of the standard deviation.

\begin{tabular}{lllllll}
\hline & Band 1 & ASM (TF1) & Ent (TF1) & Cor (TF1) & Con (TF1) & Stdev \\
\hline Band 1 & 1.00 & -0.84 & 0.79 & -0.56 & 0.21 & 508.74 \\
ASM (TF1) & 0.21 & -0.34 & 0.44 & -0.25 & 1.00 & 0.42 \\
Ent (TF1) & 0.79 & -0.94 & 1.00 & -0.66 & 0.44 & 1.69 \\
Cor (TF1) & -0.84 & 1.00 & -0.94 & 0.74 & -0.34 & 0.32 \\
Con (TF1) & -0.56 & 0.74 & -0.66 & 1.00 & -0.25 & 11.32 \\
\hline
\end{tabular}

Table 5: Combinations of texture and spectral images classified by SVM.

\begin{tabular}{lllllll}
\hline Combinations & SF & ASM & Ent & Cor & Con & Overall Feature Amounts \\
\hline C1 & SF & - & - & - & - & 7 \\
C2 & SF & ASM & - & - & - & 14 \\
C3 & SF & - & Ent & - & - & 14 \\
C4 & SF & - & - & Cor & - & 14 \\
C5 & SF & - & - & - & Con & 14 \\
C6 & SF & - & Ent & - & Con & 21 \\
C7 & SF & - & Ent & Cor & Con & 28 \\
C8 & SF & ASM & Ent & Cor & Con & 35 \\
\hline
\end{tabular}

Table 6: Training sample amounts for per class.

\begin{tabular}{ll}
\hline Classes & Training Sample Amounts \\
\hline$€-0$ & 2950 \\
$\mathrm{~S}$ & 2189 \\
$\mathrm{D}$ & 1008 \\
$\mathrm{C}-\mathrm{P}$ & 1106 \\
$\mathrm{~N}_{2}$ & 480 \\
$\mathrm{Q}_{1}$ & 1392 \\
$\mathrm{Q}_{3-4}$ & 3057 \\
\hline Total & 12182 \\
\hline
\end{tabular}

2.5.2, Section 4.2, and ranges of ASM, Ent, Cor, and Con values, sample purification rules were created, detailed in Table 9.
Table 7: Information needed to calculate sample size from Equation (9). The information contains the occupied area proportions $\left(W_{i}\right)$, mean values of user's accuracies $\left(U_{i}\right)$, and standard deviations $\left(S_{i}\right)$ of the class.

\begin{tabular}{llll}
\hline Class (i) & $\mathrm{W}_{i}$ & $\mathrm{U}_{i}$ & $\mathrm{~S}_{i}$ \\
\hline$\epsilon-0$ & 0.22 & 0.80 & 0.40 \\
$\mathrm{~S}$ & 0.11 & 0.91 & 0.29 \\
$\mathrm{D}$ & 0.06 & 0.90 & 0.33 \\
$\mathrm{C}-\mathrm{P}$ & 0.06 & 0.47 & 0.50 \\
$\mathrm{~N}_{2}$ & 0.04 & 0.50 & 0.50 \\
$\mathrm{Q}_{1}$ & 0.16 & 0.63 & 0.49 \\
$\mathrm{Q}_{3-4}$ & 0.35 & 0.94 & 0.24 \\
\hline
\end{tabular}


Table 8: Sample set size of samples A1, A2, B1, and B2; sample A1 and B1 are the original sample set; samples A2 and B2 are the sample set with sample purification.

\begin{tabular}{|c|c|c|c|c|}
\hline \multirow{2}{*}{ Class } & \multicolumn{2}{|c|}{ Simple Random Sampling } & \multicolumn{2}{|c|}{ Stratified Sampling } \\
\hline & Sample A1 & Sample A2 & Sample B1 & Sample B2 \\
\hline$\epsilon-0$ & 83 & 83 & 274 & 273 \\
\hline$S$ & 41 & 41 & 137 & 137 \\
\hline D & 20 & 20 & 75 & 75 \\
\hline C-P & 19 & 19 & 75 & 70 \\
\hline $\mathrm{N}_{2}$ & 14 & 11 & 50 & 46 \\
\hline$Q_{1}$ & 35 & 35 & 200 & 198 \\
\hline$Q_{3-4}$ & 83 & 83 & 435 & 435 \\
\hline Total & 295 & 292 & 1246 & 1235 \\
\hline
\end{tabular}

Table 9: Sample purification rules.

\begin{tabular}{lllll}
\hline Class & ASM & Ent & Cor & Con \\
\hline$\epsilon-0$ & $0.003<$ TF1-7<0.1 & - & - & - \\
$\mathrm{S}$ & - & - & - & - \\
$\mathrm{D}$ & TF1-7 $>0.01$ & - & - & - \\
$\mathrm{C}-\mathrm{P}$ & $0.01<$ TF1-7 $<0.1$ & - & - & - \\
$\mathrm{N}_{2}$ & $0.003<\mathrm{TF1} 1-7<0.1$ & TF1-7 $>4$ & TF1-2 $<0.7$ & TF1-7 $>6$ \\
$\mathrm{Q}_{1}$ & $0.005<$ TF1-7 $<0.1$ & - & - & TF1-7 $>3$ \\
$\mathrm{Q}_{3-4}$ & TF1-7 $>0.01$ & TF5-6<5.5 & - & - \\
\hline
\end{tabular}

\section{Discussion}

\subsection{Verification of Texture Window Size Selection Method Based on Semivariogram}

To verify the effectiveness of the semivariogram-based texture extraction window selection method, different ASMs with different window sizes combined with spectral features are classified by SVM. To reduce computation of verification, ASM extractions are based on window size from $5 \times 5$ to $41 \times 41$ with a step of 6 . To maintain the comparability between different classification results, the training and test sample sets were the same. The test sample set used is sample B2. Table 10 demonstrates the overall accuracies (OA) and kappa with different ASM window sizes in SVM based supervised classifications.

Table 10 shows the change in OA and Kappa with the change of ASM extraction window in SVM classifications. The highest OA is $88.09 \%$ corresponding to the texture extraction window of $23 \times 23$, which is just one of the preestimated window sizes. The second highest OA is $88.01 \%$ corresponding to the texture extraction window of $29 \times 29$, which is very close to the pre-estimated window of $31 \times 31$.
Table 10: Classification accuracies of images which ASM extracted from different windows respectively combined with spectral feature.

\begin{tabular}{llc}
\hline Window sizes & OA & Kappa \\
\hline $5 \times 5$ & $85.49 \%$ & 0.82 \\
$11 \times 11$ & $87.12 \%$ & 0.84 \\
$17 \times 17$ & $87.44 \%$ & 0.84 \\
$23 \times 23$ & $88.09 \%$ & 0.85 \\
$29 \times 29$ & $88.01 \%$ & 0.85 \\
$31 \times 31$ & $88.01 \%$ & 0.85 \\
$35 \times 35$ & $88.01 \%$ & 0.85 \\
$41 \times 41$ & $87.60 \%$ & 0.84 \\
\hline
\end{tabular}

The experiment results verified that the spatial statisticsbased texture window size pre-estimation is effective.

\subsection{Benefit of Sample Purification}

Figure 10 shows the OA and kappa of different combinations derived from test samples A1, A2, B1, and B2. As shown in the figure, the OA and Kappa obtained from the four test samples are different for the same classification result. The differences between samples A1 and B1, or samples A2 and B2 may result from the difference of sample 
set size and sampling method. For accuracies derived from samples A1 and A2, or samples B1 and B2, the difference may due to sample purification. The OA and Kappa derived from test samples with sample purification are higher than original test samples, because the error in the test samples that have been purified is smaller than those that have not. The error of test sample will reduce classification accuracy. After sample purification, the error of samples A2 and B2 is smaller than original test samples. Accuracies based on samples A2 and B2, which reduced the error of test samples, is more precise than that based on original test samples.

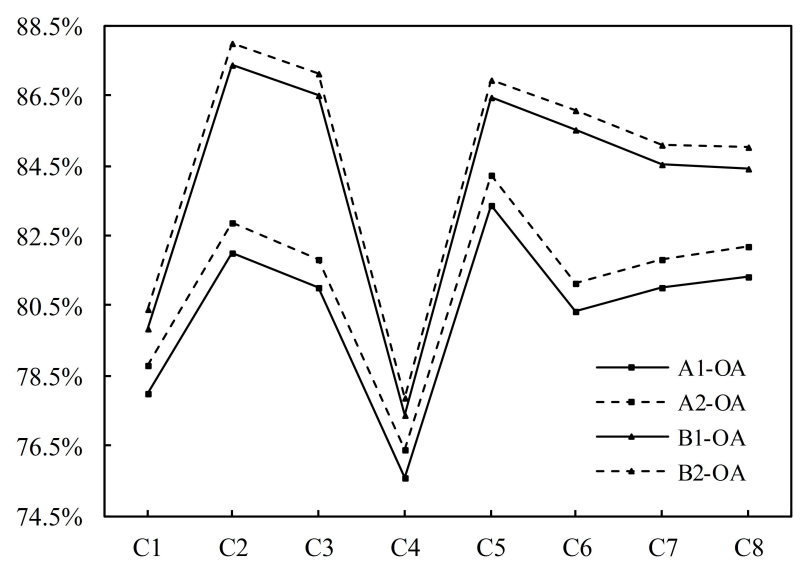

(a)

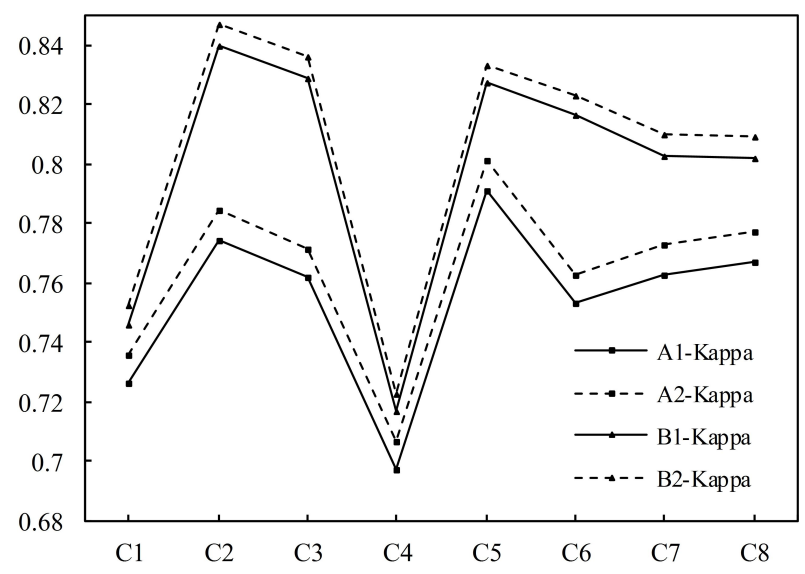

(b)

Figure 10: The overall accuracies (OA) and kappa of different combinations derived from test samples A1, A2, B1, and B2: (a) OA curves; (b) kappa curves. Sample A1 and B1 are the original sample set selected by simple random sampling and stratified sampling, sample $A 2$ and $B 2$ are the sample set with sample purification selected by simple random sampling and stratified sampling. $C i$ is the different combinations classified by SVM, detailed in Table 5 .
Table 11 demonstrates the PA and UA of different classifications obtained from samples B1. Table 12 shows the PA and UA of different classifications obtained from samples B2. By analyzing Table 11 and 12, it can be explicitly seen that UA and PA for lithostratigraphic classification have been improved when the ASM feature is added. Regardless of whether the texture features were added or not, the recognition accuracies of $\mathrm{S}$ and $\mathrm{D}$ is relatively high. This may be due to their prominent color features. When combined with texture features, the recognition accuracy of $€-O$ and $Q_{3-4}$ is significantly improved. It may result from their different s urface r oughness, which would assist rock. For C-P and $\mathrm{N}_{2}$, their texture features are similar to $Q_{1}$, and the spectral characteristics of C-P are similar to $€-O$, resulted in their poor classification accuracy. Furthermore, besides $U A$ for $\mathrm{N}_{2}$ and $\mathrm{Q}_{1}$, the rest of the features were also improved after the test samples were purified. In s ummary, lithostratigraphic classification combined with test sample purification is m ore reliable for lithostratigraphic identification.

\subsection{Effect of Texture features for Lithostratigraphic Classification}

According to Figures 11 and 12, it also can be seen that lithostratigraphic classification accuracy has improved when spectral features are combined with textural features, except when the Cor feature is used. We concluded that when the selected suitable textural features are fused with spectral features classification accuracy is improved. In this study area, ASM, Ent, and Con are suitable textural features and Cor is an unsuitable textural feature for lithostratigraphic classification. Accuracy of SF + Ent+ Con is higher than SF+ Ent+ Cor+ Con and SF+ ASM+ Ent+ Con+ Cor, and it may cause by possible conflicts between ASM, Ent, Con, and Cor.

The classification results of only spectral features and spectral features fused with different textures are shown in Figure 11. The error of classification mainly occurs in the boundary of each rock, which is not random. Figure $11 \mathrm{C} 2$ is the classification result of SF+ ASM, which is closest to the actual lithostratigraphic distribution. Furthermore, Figure 11C3 and C6 which was respectively the classification results of $\mathrm{SF}+\mathrm{Ent}$ and $\mathrm{SF}+\mathrm{Ent}+\mathrm{Con}$, is also very close to the reference map. Figure $11 \mathrm{C} 4, \mathrm{C} 7$, and $\mathrm{C} 8$, the classification result of $\mathrm{SF}+\mathrm{Cor}, \mathrm{SF}+\mathrm{Ent}+\mathrm{Cor}$, and $\mathrm{SF}+\mathrm{Ent}+\mathrm{Cor}+$ Con, have serious salt and pepper effect. It may result from that Cor feature is not conducive to the separation of rocks. 
Table 11: The producer's and user's accuracies (PA and UA) of Ci classification derived from test samples without sample purification selected by stratified sampling (sample B1); Ci means different combinations classified by SVM, detailed in Table 5.

\begin{tabular}{lllllllll}
\hline \multirow{2}{*}{ Classes } & C1 $(\%)$ & & C2(\%) & \multicolumn{3}{c}{ C3(\%) } & \multicolumn{3}{c}{ C4(\%) } \\
\cline { 2 - 9 } & PA & UA & PA & UA & PA & UA & PA & UA \\
\hline E-O & 73.36 & 81.05 & 83.21 & 91.57 & 85.4 & 91.76 & 85.77 & 81.6 \\
$\mathrm{~S}$ & 97.81 & 87.58 & 95.62 & 91.61 & 94.16 & 89.58 & 91.24 & 71.43 \\
$\mathrm{D}$ & 98.67 & 93.67 & 97.33 & 98.65 & 89.33 & 97.1 & 86.67 & 90.28 \\
$\mathrm{C}-\mathrm{P}$ & 53.33 & 45.98 & 56 & 43.3 & 54.67 & 40.59 & 64 & 42.48 \\
$\mathrm{~N}_{2}$ & 52 & 44.07 & 44 & 56.41 & 44 & 68.75 & 48 & 63.16 \\
$\mathrm{Q}_{1}$ & 82.5 & 72.37 & 86.5 & 81.99 & 88.5 & 77.63 & 74 & 66.67 \\
$\mathrm{Q}_{3-4}$ & 81.61 & 90.56 & 96.55 & 97 & 93.79 & 97.84 & 73.33 & 94.38 \\
\hline \hline \multirow{2}{*}{ Classes } & $\mathrm{C} 5(\%)$ & & $\mathrm{C} 6(\%)$ & & $\mathrm{C} 7(\%)$ & & $\mathrm{C}(\%)$ & \\
\cline { 2 - 9 } & $\mathrm{PA}$ & $\mathrm{UA}$ & $\mathrm{PA}$ & $\mathrm{UA}$ & $\mathrm{PA}$ & $\mathrm{UA}$ & $\mathrm{PA}$ & $\mathrm{UA}$ \\
\hline $\mathrm{\epsilon}-\mathrm{O}$ & 87.59 & 89.22 & 85.4 & 91.41 & 87.23 & 89.85 & 86.86 & 89.81 \\
$\mathrm{~S}$ & 97.08 & 92.36 & 94.89 & 85.53 & 89.78 & 79.35 & 88.32 & 79.08 \\
$\mathrm{D}$ & 93.33 & 97.22 & 89.33 & 100 & 86.67 & 98.48 & 86.67 & 98.48 \\
$\mathrm{C}-\mathrm{P}$ & 52 & 43.82 & 61.33 & 41.44 & 62.67 & 40.87 & 61.33 & 40 \\
$\mathrm{~N}_{2}$ & 44 & 66.67 & 46 & 76.67 & 44 & 68.75 & 44 & 68.75 \\
$\mathrm{Q}_{1}$ & 85 & 77.63 & 81.5 & 75.46 & 74.5 & 80.54 & 74.5 & 80.54 \\
$\mathrm{Q}_{3-4}$ & 92.64 & 95.95 & 92.64 & 97.34 & 93.79 & 95.55 & 94.48 & 95.58 \\
\hline
\end{tabular}

Table 12: The producer's and user's accuracies (PA and UA) of Ci classification derived from test samples with sample purification selected by stratified sampling (sample B2); Ci means different combinations classified by SVM, detailed in Table 5 .

\begin{tabular}{lllllllll}
\hline \multirow{2}{*}{ Classes } & C1(\%) & \multicolumn{3}{c}{ C2(\%) } & \multicolumn{3}{c}{ C3(\%) } & \multicolumn{3}{c}{ C4(\%) } \\
\cline { 2 - 9 } & PA & UA & PA & UA & PA & UA & PA & UA \\
\hline$\epsilon-0$ & 73.63 & 82.38 & 83.52 & 93.06 & 85.71 & 93.23 & 85.71 & 82.11 \\
$\mathrm{~S}$ & 97.81 & 87.58 & 95.62 & 91.61 & 94.16 & 89.58 & 91.24 & 71.84 \\
$\mathrm{D}$ & 98.67 & 93.67 & 97.33 & 98.65 & 89.33 & 97.1 & 86.67 & 90.28 \\
$\mathrm{C}-\mathrm{P}$ & 57.14 & 46.51 & 60 & 43.75 & 58.57 & 41 & 68.57 & 42.86 \\
$\mathrm{~N}_{2}$ & 54.35 & 43.86 & 45.65 & 55.26 & 45.65 & 67.74 & 50 & 62.16 \\
$\mathrm{Q}_{1}$ & 82.32 & 72.44 & 86.36 & 82.21 & 88.38 & 77.78 & 74.24 & 67.74 \\
$\mathrm{Q}_{3-4}$ & 81.61 & 91.03 & 96.55 & 97.67 & 93.79 & 98.55 & 73.33 & 94.66 \\
\hline \hline Classes & $\mathrm{C} 5(\%)$ & & $\mathrm{C} 6(\%)$ & & $\mathrm{C}(\%)$ & & $\mathrm{C} 8(\%)$ & \\
\cline { 2 - 9 } & $\mathrm{PA}$ & $\mathrm{UA}$ & $\mathrm{PA}$ & $\mathrm{UA}$ & $\mathrm{PA}$ & $\mathrm{UA}$ & $\mathrm{PA}$ & $\mathrm{UA}$ \\
\hline $\mathrm{E}-\mathrm{O}$ & 87.55 & 90.53 & 85.71 & 92.13 & 87.55 & 90.53 & 87.18 & 90.49 \\
$\mathrm{~S}$ & 97.08 & 92.36 & 94.89 & 85.53 & 89.78 & 79.35 & 88.32 & 79.08 \\
$\mathrm{D}$ & 93.33 & 97.22 & 89.33 & 100 & 86.67 & 98.48 & 86.67 & 98.48 \\
$\mathrm{C}-\mathrm{P}$ & 55.71 & 43.82 & 64.29 & 41.28 & 65.71 & 40.71 & 64.29 & 39.82 \\
$\mathrm{~N}_{2}$ & 45.65 & 65.63 & 47.83 & 75.86 & 45.65 & 67.74 & 45.65 & 67.74 \\
$\mathrm{Q}_{1}$ & 84.85 & 78.14 & 81.31 & 75.94 & 74.75 & 81.32 & 74.75 & 81.32 \\
$\mathrm{Q}_{3-4}$ & 92.64 & 96.41 & 92.64 & 98.05 & 93.79 & 96.45 & 94.48 & 96.48 \\
\hline
\end{tabular}

Figure 12 shows the local comparison with reference map, the classification results of spectral features, and of $\mathrm{SF}+\mathrm{ASM}$. In classification results of spectral features and $\mathrm{SF}+\mathrm{ASM}$, recognition of $\mathrm{N}_{2}$ and C-P are poor. Identification of $\mathrm{N}_{2}$ and C-P have been improved, and C-P misclas- sified as $Q_{1}$ is also slightly reduced when ASM feature is added. Moreover, recognition of $\mathrm{Q}_{3-4}$ and $\epsilon-\mathrm{O}$ are significantly improved, and $\mathrm{Q}_{3-4}$ misclassified into $\mathrm{Q}_{1}, \mathrm{~N}_{2}$, and $\mathrm{D}$ is notably reduced, and the internal salt and pepper effect is also obviously reduced. 

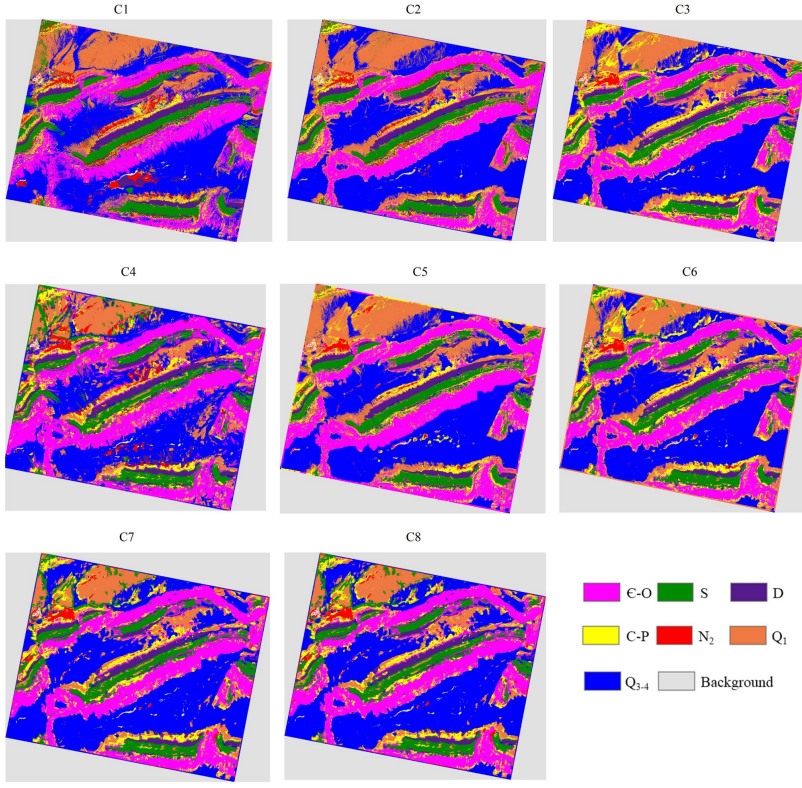

Figure 11: Classification results of different combinations classified by SVM; Ci means different combinations classified by SVM, detailed in Table 5.

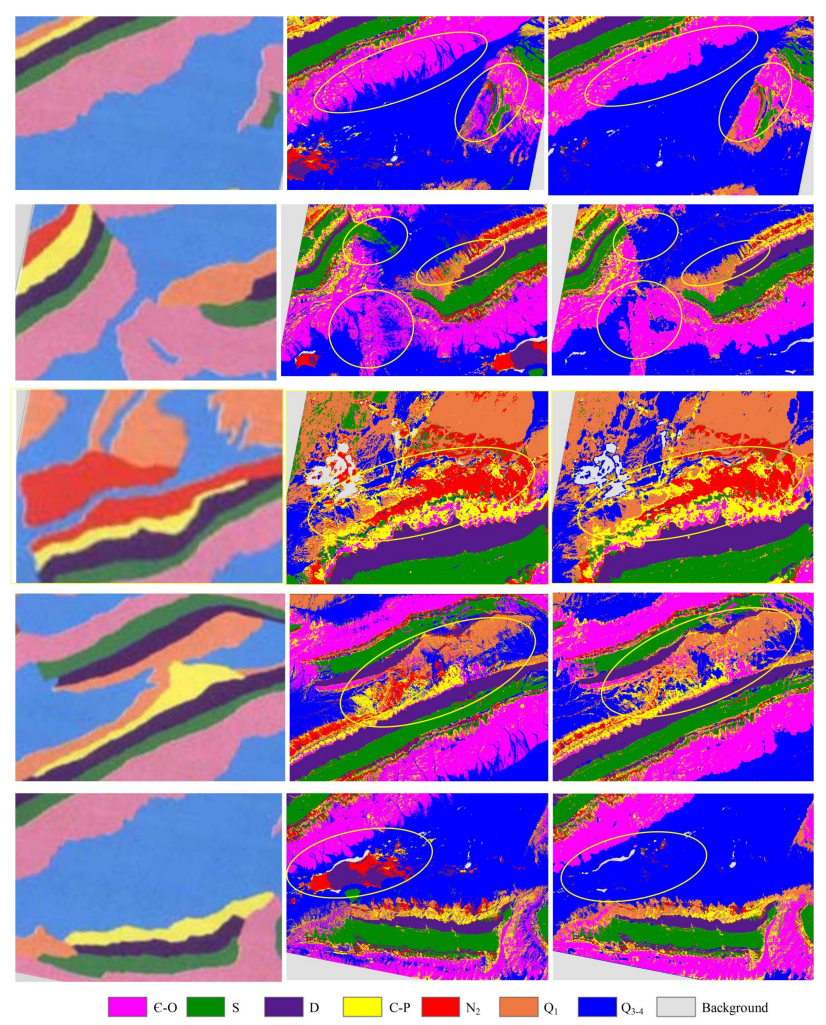

Figure 12: Zoom-in and comparison of reference map and classification results of: (a) reference map; (b) SVM with only spectral features (SF); and (c) SVM with spectral features fused with ASM $(\mathrm{SF}+\mathrm{ASM})$.
Improved accuracy is obtained when the spectral features and suitable texture feature are integrated in SVM for lithological classification. The accuracy is highest when using SF+ ASM for lithological classification. This can be attributed to two factors. The first factor is that the texture features keeps the separability of objects, as they reveal structure information of objects and their relationship with the surrounding environment in image. The second factor is that there is a large difference in the uniformity of gray distribution or texture thickness between different rocks in the study area, so that SF+ ASM yields the highest classification accuracy.

\section{Conclusions}

Remote sensing images provide a wealth of spectral information that can be used for lithostratigraphic classification, but when using only spectral information, classification accuracy is limited. It is practically significant to employ spectral features and suitable textural features with suitable window size to improve classification accuracy. Additionally, in the accuracy assessment, a test sample set is usually regarded as true and accurate. However, it contains error samples. Therefore, sample purification combined within an accuracy assessment can ensure the credibility of accuracy assessment for lithological classification.

Before texture extraction, reasonable window size was pre-estimated by the semivariogram method. Semivariogram method can be used for pre-estimation of optimal texture window size, which is theoretically and practically feasible. Classifications based on ASM of different window sizes combined with spectral features were employed to verify the effectiveness of the semivariogram-based texture extraction window selection method. According to the experimental results, we can conclude that the preestimated extraction window reflects the scale of local structure. Although pre-estimated extraction window size does not absolutely guarantee the highest classification accuracy, it does guarantee an accurate level that is either exactly or close to the optimal accuracy. Secondly, other than the window selection based on post image classification evaluations, this method avoids the time-consuming trial-and-error practice, so that it speeds up the texture extraction procedure. Besides, it is essentially data-driven method and it requires almost no priori knowledge, so it can enhance the efficiency and automatic degree of texture extraction. 
In this paper, four sets of test samples, included test samples with and without sample purification respectively, were selected by simple random sampling and stratified sampling to carry out accuracy assessments and comparisons. For one classification task, the results of the accuracy assessment obtained from four test samples were different. The difference in the results between the original test samples selected by simple random sampling and stratified sampling shows that test sample size and sampling method will affect the accuracy assessment results. The results of the accuracy assessment by using the test samples with sample purification were higher than those by using the original test samples. After sample purification, the errors of the test sample were reduced, and the results of the accuracy assessment were more reliable and accurate. The proposed lithostratigraphic classification method combined with test sample purification is meaningful for lithostratigraphic identification.

In this study, the features used for sample purification are not plentiful. Therefore, in the future work, the features should be enriched and the feature selection method should be combined with the process of sample purification rules creation.

Acknowledgement: This work is supported by the National Natural Science Foundation of China (41671369) and "the Fundamental Research Funds for the Central Universities". The authors are thankful to USGS EROS data center for providing Landsat 8 data. The authors wish to thank the reviewers for their constructive comments that helped improve the scholarly quality of the paper. Their generous contribution of time and expertise are greatly appreciated.

\section{References}

[1] Basavarajappa HT, Narayan JL, Rajendran S, Manjunatha MC. Discrimination of Banded Magnetite Quartzite (BMQ) Deposits and Associated Lithology of Parts of Chikkanayakanahalli Schist Belt of Dharwar Craton, Karnataka, India using Remote Sensing Technique. 2015;2015:1033-44.

[2] Bertoldi L, Massironi M, Visonà D, et al. Mapping the Buraburi in the Himalaya of Western Nepal: Remote Sensing analysis in a collisional belt with vegetation cover and extreme variation of topography. Remote Sensing of Environment 2011;115:1129-44.

[3] Honarmand M, Ranjbar H, Shahabpour J. Combined use of ASTER and ALI data for hydrothermal alteration mapping in the northwestern part of the Kerman magmatic arc, Iran. International Journal of Remote Sensing 2013;34:2023-46.

[4] Manjunatha MC, Basavarajappa HT. Spatial data integration of lithology, geomorphology and its impact on groundwater prospect zones in precambrian terrain of chitradurga district, karnataka, india using geomatics application. Global Journal of
Engineering Science \& Research Management 2015;2:16-22.

[5] Massironi M, Bertoldi L, Calafa P, et al. Interpretation and processing of ASTER data for geological mapping and granitoids detection in the Saghro massif (eastern Anti-Atlas, Morocco). Geosphere 2008;4:736-59.

[6] Mehdi H, Hojjatollah R, Jamshid S. Application of Principal Component Analysis and Spectral Angle Mapper in the Mapping of Hydrothermal Alteration in the Jebal-Barez Area, Southeastern Iran. Resource Geology 2012;62:119-39.

[7] Pournamdari M, Hashim M. Detection of chromite bearing mineralized zones in Abdasht ophiolite complex using ASTER and ETM + remote sensing data. Arabian Journal of Geosciences 2014;7:1973-83.

[8] Shahriari H, Honarmand M, Ranjbar H. Comparison of multitemporal ASTER images for hydrothermal alteration mapping using a fractal-aided SAM method. International Journal of Remote Sensing 2015;36:1271-89.

[9] Shahriari H, Ranjbar H, Honarmand M, Carranza EJM. Selection of Less Biased Threshold Angles for SAM Classification Using the Real Value-Area Fractal Technique. Resource Geology 2014;64:301-15.

[10] Yajima T, Yamaguchi Y. Geological mapping of the Francistown area in northeastern Botswana by surface temperature and spectral emissivity information derived from Advanced Spaceborne Thermal Emission and Reflection Radiometer (ASTER) thermal infrared data. Ore Geology Reviews 2013;53:134-44.

[11] Rowan LC, Mars JC. Lithologic mapping in the Mountain Pass, California area using Advanced Spaceborne Thermal Emission and Reflection Radiometer (ASTER) data. Remote Sensing of Environment 2003;84:350-66.

[12] Smith JR, Chang SF. Automated binary texture feature sets for image retrieval. IEEE International Conference on Acoustics, Speech, and Signal Processing, 1996 Icassp-96 Conference Proceedings; 1996. p. 2239-42.

[13] Haralick RM. Texture features for image classification. Systems Man \& Cybernetics IEEE Transactions on 1973;smc-3:610-21.

[14] Huang YD, Pei-Jun LI, Zheng-Xiao LI. The application of geostatistical image texture to remote sensing lithological classification. Remote Sensing for Land \& Resources 2003;15:45-9.

[15] Li N, Frei M, Altermann W. Textural and knowledge-based lithological classification of remote sensing data in Southwestern Prieska sub-basin, Transvaal Supergroup, South Africa. Journal of African Earth Sciences 2011;60:237-46.

[16] Perez CA, Saravia J, Navarro C, Castillo L, Schulz D, Aravena C. Lithological classification based on Gabor texture image analysis. 2012 International Symposium on Optomechatronic Technologies (ISOT 2012); 2012 29-31 Oct. 2012. p. 1-3.

[17] Perez CA, Saravia JA, Navarro CF, Schulz DA, Aravena CM, Galdames FJ. Rock lithological classification using multi-scale Gabor features from sub-images, and voting with rock contour information. International Journal of Mineral Processing 2015;144:56-64.

[18] Shankar V. Texture-Based Automated Lithological Classification Using Aeromagenetic Anomaly Images: USA:U.S. Geological Survey; 2009.

[19] Wei JL, Liu XN, Liu JL. Integrating Textural and Spectral Features to Classify Silicate-Bearing Rocks Using Landsat 8 Data. Appl Sci-Basel 2016;6:17.

[20] Mather PM, Tso B, Koch M. An evaluation of Landsat TM spectral data and SAR-derived textural information for lithological dis- 
crimination in the Red Sea Hills, Sudan. International Journal of Remote Sensing 1998;19:587-604.

[21] Dongping M, Tianyu C, Hongyue C, Longxiang L, Cheng Q, Jinyang D. Semivariogram-Based Spatial Bandwidth Selection for Remote Sensing Image Segmentation With Mean-Shift Algorithm. IEEE Geoscience and Remote Sensing Letters 2012;9:8137.

[22] Dihkan M, Guneroglu N, Karsli F, Guneroglu A. Remote sensing of tea plantations using an SVM classifier and pattern-based accuracy assessment technique. International Journal of Remote Sensing 2013;34:8549-65.

[23] Yu L, Porwal A, Holden EJ, Dentith MC. Towards automatic lithological classification from remote sensing data using support vector machines. Computers \& Geosciences 2012;45:229-39.

[24] Godarzi MS, Abbaspour RA, Ahadnezhad V, Khakbaz B. Comparison of support vector machine, neural network, and maximum likelihood methods for the separation of lithological units. Iranian Journal of Geology 2012;6:75-92.

[25] Mondal A, Kundu S, Chandniha SK, Shukla R, Mishra PK. Comparison of support vector machine and maximum likelihood classification technique using satellite imagery. Journal of Molecular \& Cellular Cardiology 2012;1:116-23.

[26] Mou D, Wang ZW, Huang YL, Xu S, Zhou DP. Lithological identification of volcanic rocks from SVM well logging data: Case study in the eastern depression of Liaohe Basin. Chinese Journal of Geophysics- Chinese Edition 2015;58:1785-93.

[27] Othman A, Gloaguen R. Improving Lithological Mapping by SVM Classification of Spectral and Morphological Features: The Discovery of a New Chromite Body in the Mawat Ophiolite Complex (Kurdistan, NE Iraq). Remote Sensing 2014;6:6867-96.

[28] Othman A, Gloaguen R. Improving Lithological Mapping by SVM Classification of Spectral and Morphological Features: The Discovery of a New Chromite Body in the Mawat Ophiolite Complex (Kurdistan, NE Iraq). Remote Sensing 2014;6:6867.

[29] Deng C, Pan H, Fang S, Amara Konaté A, Qin R. Support vector machine as an alternative method for lithology classification of crystalline rocks. Journal of Geophysics \& Engineering 2017;14:341-9.

[30] Othman AA, Gloaguen R. Integration of spectral, spatial and morphometric data into lithological mapping: A comparison of different Machine Learning Algorithms in the Kurdistan Region, NE Iraq. Journal of Asian Earth Sciences 2017;146:90-102.

[31] Othman A, Gloaguen R. Comparison of Different Machine Learning Algorithms for Lithological Mapping Using Remote Sensing Data and Morphological Features: A Case Study in Kurdistan Region, NE Iraq. EGU; 2015.

[32] Wang YY, Jing LI. Classification Methods of Land Use/Cover Based on Remote Sensing Technology. Remote Sensing Information 2004:53-7.

[33] Rwanga SS, Ndambuki JM. Accuracy Assessment of Land Use/Land Cover Classification Using Remote Sensing and GIS. International Journal of Geosciences 2017;8:611-22.

[34] Stehman SV, Czaplewski RL. Design and Analysis for Thematic Map Accuracy Assessment : Fundamental Principles. Remote Sensing of Environment 1998;64:331-44.

[35] Foody GM. Status of land cover classification accuracy assessment. Remote Sensing of Environment 2002;80:185-201.

[36] Stehman SV. Basic probability sampling designs for thematic map accuracy assessment. International Journal of Remote Sensing 1999;20:2423-41.
[37] Lyons MB, Keith DA, Phinn SR, Mason TJ, Elith J. A comparison of resampling methods for remote sensing classification and accuracy assessment. Remote Sensing of Environment 2018;208:145-53.

[38] Pontius RG, Millones M. Death to Kappa: birth of quantity disagreement and allocation disagreement for accuracy assessment. International Journal of Remote Sensing 2011;32:440729.

[39] Foody GM. Sample size determination for image classification accuracy assessment and comparison. International Journal of Remote Sensing 2009;30:5273-91.

[40] Olofsson P, Foody GM, Herold M, Stehman SV, Woodcock CE, Wulder MA. Good practices for estimating area and assessing accuracy of land change. Remote Sensing of Environment 2014;148:42-57.

[41] Sarp G, Erener A. The Effects of Sample Size Selection on Classification Accuracy. Elib Tiho 2012;30:374-9.

[42] Stehman SV. Sampling designs for accuracy assessment of land cover. International Journal of Remote Sensing 2009;30:524372.

[43] Adiri Z, El Harti A, Jellouli A, Maacha L, Bachaoui EM. Lithological mapping using Landsat $8 \mathrm{OLI}$ and Terra ASTER multispectral data in the Bas Drâa inlier, Moroccan Anti Atlas. Journal of Applied Remote Sensing 2016;10:016005-.

[44] El-Leil I, Soliman NM, Elyaseer MH. Lithological Classification of Neoproterozoic Rocks, Gabal El-Sabbagh Area, South East Sinai Egypt, using Support Vector Machine (SVM) Technique. IJISETInternational Journal of Innovative Science, Engineering \& Technology 2015;2:906-17.

[45] Roy DP, Wulder MA, Loveland TR, et al. Landsat-8: Science and product vision for terrestrial global change research. Remote Sensing of Environment 2014;145:154-72.

[46] United States Geological Survey (USGS) and Earth Resources Observation and Science (EROS) data center. Available online: http://glovis.usgs.gov/

[47] Georges M. Principles of geostatistics. Economic geology 1963;58:1246-4.

[48] Mohanaiah P, Sathyanarayana P, GuruKumar L. Image texture feature extraction using GLCM approach. International Journal of Scientific and Research Publications 2013;3:1-5.

[49] Xianmin Wang RN. Classification rule mining of lithology by remote sensing image in Three Gorges. Computer Engineering and Applications 2008;44:13-6.

[50] Tetuko J. Analysis of co-occurrence and discrete wavelet transform textures for differentiation of forest and non-forest vegetation in very-high-resolution optical-sensor imagery. International Journal of Remote Sensing 2008;29:3417-56.

[51] Ming D, Zhou T, Wang M, Tan T. Land cover classification using random forest with genetic algorithm-based parameter optimization. Journal of Applied Remote Sensing 2016;10:035021.

[52] Wang L, Tian X, Wang W, Li Y. Evaluation of machined surface quality of Si $3 \mathrm{~N} 4$ ceramics based on neural network and grey-level co-occurrence matrix. The International Journal of Advanced Manufacturing Technology 2017;89:1661-8.

[53] Wang Y, Xia H, Yuan X, Li L, Sun B. Distributed defect recognition on steel surfaces using an improved random forest algorithm with optimal multi-feature-set fusion. Multimedia Tools and Applications 2018;77:16741-70.

[54] Boser BE, Guyon IM, Vapnik VN. A training algorithm for optimal margin classifiers. Proceedings of the fifth annual work- 
shop on Computational learning theory; 1992; Pittsburgh, PA, USA: ACM. p. 144-52.

[55] Schiilkop P, Burgest C, Vapnik V. Extracting support data for a given task. Proceedings, First International Conference on Knowledge Discovery \& Data Mining AAAl Press, Menlo Park, CA; 1995 20-21 August; Montreal, PQ, Canada. p. 252-7.

[56] Cortes C, Vapnik V. Support-vector networks. Machine learning 1995;20:273-97.

[57] Vapnik VN. The Vicinal Risk Minimization Principle and the SVMs: Springer New York; 2000.

[58] Osuna E, Freund R, Girosi F. Training Support Vector Machines: an Application to Face Detection. Computer Vision and Pattern Recognition, 1997 Proceedings, 1997 IEEE Computer Society Conference on; 2002 17-19 June 1997; San Juan, Puerto Rico, USA. p. 130-6.

[59] Cochranwrited W. Sampling Techniques.3rd ed: John Wiley \& Sons; 1977.

[60] Yu H, Li P. Lithologic mapping using LANDSAT ETM + and ASTER data. Acta Petrologica Sinica 2010;26:345-51.

[61] Teillet P, Guindon B, Goodenough D. On the slope-aspect correction of multispectral scanner data. Canadian Journal of Remote Sensing 1982;8:84-106.
[62] Rouse JW. Monitoring the vernal advancement of retrogradation of natural vegetation,NASA/GSFG, Type III. Final Report 1974;371.

[63] Othman A, Gloaguen R. Automatic Extraction and Size Distribution of Landslides in Kurdistan Region, NE Iraq. Remote Sensing 2013;5:2389.

[64] Chavez P, Berlin GL, Sowers LB. Statistical method for selecting landsat MSS. J Appl Photogr Eng 1982;8:23-30.

[65] Stehman SV. Impact of sample size allocation when using stratified random sampling to estimate accuracy and area of landcover change. Remote Sensing Letters 2012;3:111-20.

[66] Card DH. Using known map category marginal frequencies to improve estimates of thematic map accuracy. Photogrammetric Engineering \& Remote Sensing 1982;48:431-9.

[67] Green EJ, Strawderman WE, Airola TM. Assessing classification probabilities for thematic maps. Photogrammetric Engineering \& Remote Sensing 1993;59:635-9.

[68] Stehman SV. Thematic map accuracy assessment from the perspective of finite population sampling. International Journal of Remote Sensing 1995;16:589-93. 